\title{
Some experience with a colorimetric method for the determination of glucose in biological fluids
}

The method of Hagedorn and Jensen for the determination of glucose in biological fluids, which is widely used in Europe, suffers from some drawbacks. The procedure is rather complex, each analytical step providing possible sources of error, and can give incorrect results at high blood levels ${ }^{1}$.

A colorimetric method for the determination of glucose, based on the formation of a yellow glucosazone, was described by WAHBA et al. ${ }^{2}$, who claimed that true glucose values are obtained with this procedure. The use of $\mathrm{I} \mathrm{ml}$ of blood and a heating time of $\mathrm{I} h$ are, however, impractical conditions for application in clinical routine.

The investigation described here was undertaken in order to make the method suitable for routine use and to check its specificity. This was achieved by reducing the heating time to Io min and the volume of blood to $0.05 \mathrm{ml}$. The use of an "all-inone" reagent was further included, thus limiting the pipetting steps and facilitating automation. The new procedure was compared with an enzymatic method ${ }^{3}$ and with the values obtained by the Hagedorn-Jensen method.

\section{METHOD}

\section{Reagents}

(I) Reagent A: $10 \%(\mathrm{w} / \mathrm{v})$ zinc acetate. (2) Reagent $\mathrm{B}$ : dissolve I $\mathrm{g}$ of phenylhydrazine hydrochloride (p.a., Merck) in $60 \mathrm{ml}$ of warm water, cool, add $2.5 \mathrm{~g}$ of sodium metabisulfite and dilute with water to $\mathrm{I}$ oo $\mathrm{ml}$. This reagent must be renewed once a week. (3) Reagent $\mathrm{C}$ : dilute $\mathrm{IO} \mathrm{ml}$ of reagent $\mathrm{B}$ with acetic acid (p.a., Merck, free from aldehyde) to Ioo $\mathrm{ml}$. This reagent must be prepared freshly every day.

\section{Procedure}

Measure $0.05 \mathrm{ml}$ of blood (or other nuid to be analysed) into $2 \mathrm{ml}$ of reagent A. Heat for $3 \mathrm{~min}$ in a boiling water bath, cool and centrifuge for $5 \mathrm{~min}$ at $3000 \mathrm{rev} / \mathrm{min}$. To $0.4 \mathrm{ml}$ of the clear supernatant liquid add $3 \mathrm{ml}$ of reagent $\mathrm{C}$, mix and heat for $30 \mathrm{~min}$ in a boiling water bath*. Cool and moasure the optical density of the solution at $396 \mathrm{~m} \mu$. A blank with $0.4 \mathrm{ml}$ of reagent $\mathrm{A}$ instead of the supernatant liquid is subtracted.

\section{Calibration}

Standard solutions of glucose are run through the same procedure. The optical density increases linearly with glucose concentration up to $500 \mathrm{mg} / \mathrm{I} 00 \mathrm{ml}$ (Beckman DU spectrophotometer).

\section{EXPERIMENTS AND DISCUSSION}

(a) Comparison of the phenylhydrazine method with the enzymatic procedure showed a good correlation (Fig. I), at least when deproteinisation was carried out in both methods as described by Somogyi and Nelson. Normal fasting levels were $66-98 \mathrm{mg} \%$. When deproteinisation was carried out with zinc acetate (which is easier

* The tubes were $15 \mathrm{~cm}$ long and they were closed with marbles. 
in routine use) blood glucose values were about $15 \mathrm{mg} \%$ higher. The normal fasting levels were $80-\mathrm{I}$ Io $\mathrm{mg} \%$, which is in close agreement with the results obtained by the Hagedorn-Jensen method. Contrary to the findings of WAHBA et al. ${ }^{2}$, it appeared that zinc acetate affects both colour formation and deproteinisation. True blood glucose values can be obtained by the method, but only under special conditions of deproteinisation.

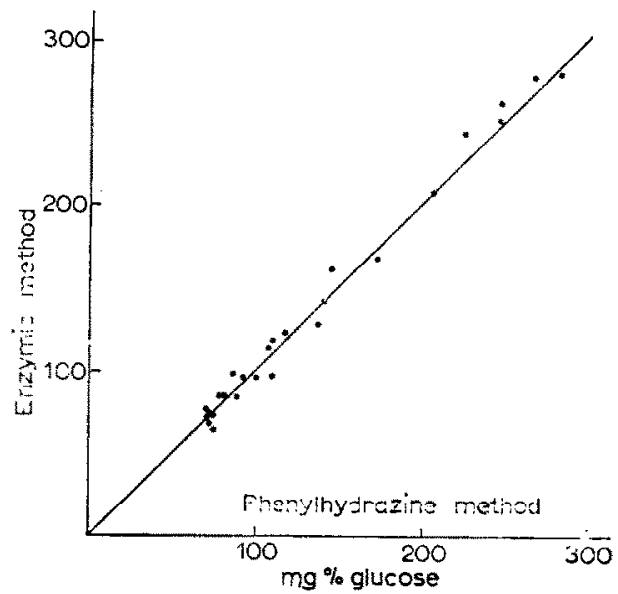

Fig. 1. Correlation between the phenyllydrazine method and a glucose oxidase method. Deproteinisation with $\mathrm{Ba}(\mathrm{OH})_{2}$ and $\mathrm{ZnSO}_{4}$.

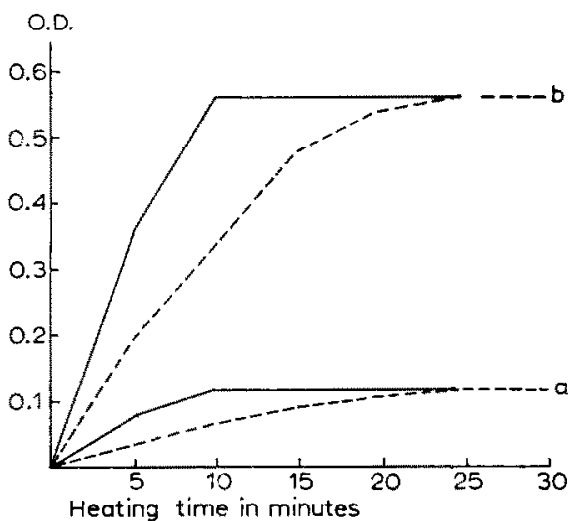

Fig. 2. Colour development with two standard glucose solutions a (10o $\mathrm{mg} \%$ ) and $\mathrm{b}(500 \mathrm{mg} \%$ ) after running through the phenylhydrazine procedure. -...- heating in a water bath at $100^{\circ}$; heating in a glycerin bath at $110^{\circ}$.

(b) The heating time for the development of the colour can be reduced successfully to ro min, when heating is not carried out in a boiling water bath, but in a constant temperature bath (with glycerin) at $110^{\circ}$. After $25 \mathrm{~min}$ at $100^{\circ}$ or 10 min at $110^{\circ}$, when the maximum colour is produced, further heating does not cause a reduction of the colour (Fig. 2).

After cooling the optical density remains stable for at least $6 \mathrm{~h}$.

(c) The method lends itself readily to automation. Blood sampling and diluting 
with reagent A) can be done with an automatic diluting pipette. Mixing of reagent $\mathrm{C}$ and deproteinised supernate can also be carried out with an automatic pipette. Measurements can be made with the aid of an automatic cuvette.

(d) Blood glucose values obtained by the method show good correlation with the values obtained with the method of Hagedorn-Jensen. Thus, the usual normal values can be maintained, when this method is introduced. The standard deviation of the method is about $3 \mathrm{mg} \%$.

(e) The recently published $o$-toluidine method $^{5}$ was also investigated in our laboratories. Comparison with the phenylhydrazine method showed blood glucose values which were $30-40 \mathrm{mg} \%$ lower (deproteinisation with zinc acetate). Moreover, the $o$-toluidine method has an optimal heating time of $8 \mathrm{~min}$; prolonged heating causes a reduction of the colour. A standard must be run through the same procedure in each series and readings should be made within $30 \mathrm{~min}$, as the colour is not stable at room temperature.

\section{CONCLUSION}

The phenylhydrazine method for the determination of glucose in biological fluids is attractive in routine analysis. The method is rapid, especially since the heating tine, necessary for colour development, can be reduced to $10 \mathrm{~min}$.

This investigation was carried out within the framework of the Buitengewone Normcommissie "Klinisch-Chemische methoden", BNC 42, van het Nederlands Normalisatie-Instituut.

Clinical-Chemical Laboratory, St. Elisabeth's Hospital, J. A. P. Stroes Haarlem H. A. ZONDAG and

Chemical Department, National Institute of Public Health, P. J. H. CHr. CORNELisseN Utrecht (The Netherlands)

1 A. H. Holtz, Ha. J. van Dreumel and E. J. van Kampen, Clin. Chim. Acta, 6 (1961) 467.

${ }^{2}$ N. Wahba, S. Hanna and M. M. El-Sadr, Analyst, 8I (1956) 430.

3 H. H. Kreutzer and M. Bosman, Ned. Tijdschr. Geneesk., I04 (1960) 379.

4 A. Mather, Am. J. Clin. Pathol., 33 (I960) I 86.

5 A. Hyvärinen and E. A. Nikkila, Clin. Chim. Acta, 7 (ig62) I 40.

Received June I2th, Ig62

Clin. Chim. Acta, 8 (I963) I $52-154$

\section{On steroid conjugates in plasma}

\section{Extraction of 17-ketosteroid conjugates}

Recently, a reversible association between dehydroepiandrosterone (DHEA) sulfate and serum albumin has been demonstrated by in vitro techniques ${ }^{1}$. At the same time solvolysable $\mathrm{I} 7$-ketosteroid ( $\mathrm{I} 7$-KS) conjugates could be extracted from native 